\title{
Dental Mesenchymal Stem Cell: Its Role in Tooth Development, Types, Surface Antigens and Differentiation Potential
}

\author{
Yohanna Feter ${ }^{1}$, Nadhia Sari Afiana ${ }^{1}$, Jessica Nathalia Chandra ${ }^{1}$, Kharima Abdullah ${ }^{1}$, Jasmine \\ Shafira ${ }^{1}$, Ferry Sandra ${ }^{2,3}$ \\ ${ }^{1}$ Faculty of Dentistry, Trisakti University, Jakarta, Indonesia \\ ${ }^{2}$ Department of Biochemistry and Molecular Biology, Division of Oral Biology, Faculty of Dentistry, Trisakti University, Jakarta, \\ Indonesia \\ ${ }^{3}$ Doctoral Program in Medical Science, Faculty of Medicine, University of Sumatera Utara, Medan, Indonesia
}

\begin{abstract}
Reciprocal interaction between oral ectodermal epithelial cells and mesenchymal stem cells (MSCs)-derived from the cranial neural crest starts the teeth development. The role of dental MSCs continues throughout life. The dental MSCs do not only play a role in tooth development but also in tooth homeostasis and repair. There are many kinds of dental MSCs, such as dental pulp stem cell (DPSC), stem cell from apical papilla (SCAP), stem cell from exfoliated deciduous teeth (SHED), periodontal ligament stem cell (PDLSC) and stem cell from dental follicle (DFSC). Aligned with the proposed criteria by the International Society for Cellular Therapy (ISCT), dental MSCs are adherent cells and like other MSCs, dental tissue MSCs are capable of giving rise to cell lineages such as osteo/odontogenic, adipogenic, and neurogenic. Various surface antigens of dental MSCs were reported, however, mostly typical antigens suggested by ISCT were fulfilled. Surface antigens from each dental MSCS (DPSC, SCAP, SHED, PDLSC and DFSC) are being described in the current report.
\end{abstract}

Keywords: dental stem cells, mesenchymal stem cells, tissue regeneration, DPSC, SCAP, SHED, PDLSC, DFSC

\section{Introduction}

Teeth are complex organs which exhibit limited repair in response to damage. It has two separate specialized hard tissues which are enamel and dentin. Enamel is formed from oral ectodermal epithelial cells which give rise to enamelforming ameloblasts. On the other hand, mesenchymal stem cells (MSCs) will form all other differentiated cells such as odontoblasts, pulp and periodontal ligament (PDL). ${ }^{1,2}$ The teeth will not stop to develop and will continue to develop postnatal, forming a tooth that is functional.

Date of submission: May 7, 2017

Accepted for publication: May 23, 2017

Corresponding Author:

Ferry Sandra

Department of Biochemistry and Molecular Biology, Division of Oral Biology

Faculty of Dentistry, Trisakti University, Jl. Kyai Tapa No.260

Jakarta, Indonesia

E-mail: ferrysandra@gmail.com
It has been proposed that the tooth might contain stem cells by an observation that teeth could do a repair process in which new odontoblasts are formed. The presence of different types of MSCs have been suggested depending on the site they have been harvested. ${ }^{3}$ Dental pulp stem cell (DPSC), one of the examples of MSCs in teeth, is considered to share the same properties with MSCs and have several therapeutic potentials. ${ }^{2}$ Thus repair, restoration and replacement of teeth are possible with the usage of stem cells. Significantly non-dental used such as stem cell-based therapies for major life-threatening disease may also be possible. $^{1}$ 
This review will outline the role of stem cells in tooth development, the importance of its biological properties, various types of dental stem cell and the criteria of dental tissue-derived MSCs.

\section{Stem cells in tooth development}

Teeth first develop through the mutual interaction between oral ectodermal epithelial cells and MSCs derived from the cranial neural crest (CNC). First, an enamel organ will be formed, followed by papilla and dental follicle. The MSCs form the most of the soft and hard tissues around and in the tooth, such as dental pulp, dentin, alveolar bone and PDL.,3, The enamel is formed by ameloblasts derived from the oral epithelium, while the dentin is synthesized by odontoblasts which derived from dental papilla and MSCs. ${ }^{5}$

The role of dental MSCs continues throughout life. The dental MSCs do not only play a role in tooth development but also in tooth homeostasis and repair. ${ }^{6}$ The cells will generate odontoblasts to repair the damaged dentin. Dental MSCs in the PDL will be involved in repairing the PDL. However, enamel can't be naturally repaired or replaced because the epithelial-derived ameloblasts are lost when the teeth erupt.

\section{Origin of dental stem cells}

MSCs are in charge of forming most of the soft and hard tissues in and around the tooth while the epithelium is in charge of mainly producing the ameloblasts. The dental MSCs are derived from two different origins which are the $\mathrm{CNC}$ and non-CNC mesoderm. The neural crest is a transitory population of cells that emerge from lateral ridges of neural plate during early embryogenesis and then differentiate into neurons, glia, melanocytes and mesenchymal cells. ${ }^{4}$ The CNC-derived mesenchyme will migrate, proliferate and differentiate into more specialized cells which are odontoblasts, cementoblasts, fibroblasts, osteoblasts and chondroblasts. ${ }^{7}$ Studies showed that CNCderived ectomesenchyme along with dental epithelium supported the tooth formation. It is proposed that CNCderived mesenchyme are odontogenic, either they possessed instructive odontogenic with the potential to initiate tooth development or possessed the ability to respond to odontogenic signals such as Fibroblast Growth Factor 8 (FGF8) to support the tooth formation. ${ }^{8}$ Besides that, the signaling of mothers against Drosophila melanogaster 4
(Smad4)-mediated Bone Morphogenic Proteins (BMP) in the CNC-derived mesenchyme is required so that the tooth development could progress into the bud stage. ${ }^{9}$ Thus, it could be said that CNC-derived mesenchyme holds a crucial role in tooth development.

During the early bud stage, the condensed dental mesenchyme is mainly populated by CNC-derived cells. ${ }^{10}$ As the tooth develop and enter the late bud stage, a significant number of CNC-derived cells with some non-CNC cells are present in the condensed dental mesenchyme. When the tooth bud continues to proliferate and enter the cap stage, the amount of non-CNC cells increase. Therefore, as the tooth develops, especially during the cap and bell stages, the blood vessels invade the dental papilla, a number of non$\mathrm{CNC}$ cells increases in the dental mesenchyme., ${ }^{711}$

A transplantation method using the LacZ ( $\beta$-galactosidase) reporter gene transgenic and wild-type mice is used to understand the origin and the migration mechanism of non-CNC-derived cells. ${ }^{7}$ Animals with the reporter gene such as lacZ are suitable for cell lineage analysis and investigation of migration, proliferation and differentiation during development and regeneration processes. ${ }^{7,10}$ The result showed that the circulating cells invade the developing dental pulp via the endothelium of the blood vessel, reside in the dental pulp, and become the non-CDC-derived cell. Thus, the study suggested that these circulating progenitor cells could be the origin of non-CNCderived cells in tooth germ. ${ }^{?}$

\section{Dental stem cells}

Adult Stem Cells (ASCs) could be found in our body tissues, such as dental tissues. Like other MSCs, dental tissue MSCs are capable of giving rise to cell lineages such as osteo/ odontogenic, adipogenic and neurogenic. ${ }^{12}$ Dental stem cells can be classified into two categories based on their differentiation potentials toward the dentin or periodontium tissues. DPSC, stem cell from apical papilla (SCAP) and stem cells from exfoliated deciduous teeth (SHED) are classified in the first category which is associated with the dental pulp complex formation. The second group, includes PDL stem cell (PDLSC) and dental follicle stem cell (DFSC), is related to the formation of the periodontium. ${ }^{13}$

\section{DPSC}

DPSC was first isolated and characterized from normal human impacted third molars. The pulp was gently separated 
from the crown and root, then digested in a solution and processed to obtain single-cell suspensions, After that it was seeded to form colonies. ${ }^{14} \mathrm{~A}$ study reported that DPSC has a higher proliferation rate, a greater clonogenic potential and a higher number of stem/progenitor cells in the population and may have increased mineralization potential compared to BMSC..$^{15}$

There are four commonly used stem cell identification techniques such as fluorescent antibody cell sorting. In this technique, stem cells can be identified and isolated from mixed cell populations by staining the cells with specific antibody markers and using a flow cytometer. Other techniques are immunomagnetic bead selection, immunohistochemical staining and physiological and histological criteria, including phenotype, proliferation, chemotaxis, mineralizing activity and differentiation. ${ }^{16}$

Several immunohistochemical studies were performed to characterize the progeny of the DPSC populations, by using a panel of antibodies specific. DPSC showed positivity markers cluster of differentiation (CD)73 and C90, CD105, CD146, stromal precursor antigen (STRO)-1, CD106, CD29, CD49, CD51, CD61, CD166, Aldehyde dehydrogenase (ALDH)1, CD44, CD9, CD10 CD13, CD59, mesenchymal stem cell antigen -1 (MSCA-1), CD81, CD24, CD271/ nerve growth factor receptor (NGFR), Nestin, doublecortin (DCX), $\beta$ III-tubulin, neuronal nuclei (NeuN), glial fibrillary acidic protein (GFAP), S-100, A2B5, 2',3'-cyclic nucleotide 3'-phosphodiesterase (CNPase), musashi-1, p75, snail family transcriptional repressor 1 (snail-1), snail-2, slug, sex determining regio Y-box 9 (Sox-9), nanog, organic cation/ carnitine transporter 3/4 (Oct3/4), stage specific embryonic antigens -1 (SSEA-1), SSEA-3, SSEA-4, SSEA-5, notch homolog-1 (Notch-1), Notch-2, Notch-3. DPSC was negative for CD14, CD19, CD34, CD45, CD117, CD133 and human leukocyte antigen - antigen D related (HLADR). ${ }^{14,17,18}$

Stem cells from the pulp are capable of differentiating in vitro and in vivo into osteoblast, which can be used directly for dental therapy. DPSC can also differentiate into adipocyte, chondrocyte, hepatocyte, dentin-pulp like, complex, neuron, cornea epithelial cell, melanoma cell and insulin-secreting beta cells. Because of this capability, DPSC can become an alternative for non-invasive source to be used for future regenerative therapies. ${ }^{14,19,20}$

\section{$S C A P$}

SCAP can be found in the developing tissue-apical papilla of immature permanent teeth. SCAP is one of the MSCs that has an important role in wound healing of incomplete tooth development. ${ }^{21}$ It is believed to be the main source of undifferentiated cells in the process of root development. ${ }^{22}$ Cells in apical papilla proliferated two to three fold greater than those in pulp in organ cultures. ${ }^{23}$

SCAP has faster cell division as well as higher population doubling level and ability to create dentin in vivo. Furthermore, the population of stem cells derived from this tissue is positive for specific markers of MSCs, such as CD146, ${ }^{21,24}$ CD44, CD73, CD90, CD105 and CD106.22 SCAP also showed negative markers of hematopoietic stem cells, mature blood cells such as CD18, CD34, CD45 and HLA-DR. ${ }^{21}$ Apical papilla is distinctive to a pulp regarding containing less cellular and vascular components than those in a pulp. ${ }^{23}$ Soft tissue from the outer apical papilla has shown positive for STRO-1 $1^{21,23,24}$ and CD24-surface markers of SCAP. These markers will be lost during cell differentiation and generate dentin. ${ }^{21}$

SCAP has the potential to differentiate into bone and dentin as the bone marrow-derived MSCs (BM-MSCs). ${ }^{22,23}$ SCAP is capable of differentiating into odontoblastic lineages in vitro and form ectopic pulp-dentine like tissue complexes when transplanted subcutaneously into immunocompromised mice in vivo. ${ }^{24}$

\section{SHED}

The presence of SHED was first identified from normal exfoliated human deciduous incisors 7 to 8 -year-old children as a population of heterogeneous cells that represent more immature stem cell population and capable of extensive proliferation and multipotential differentiation. ${ }^{25}$ SHED has several advantages over other stem cells derived from teeth because SHED is reported to have higher proliferation rate and higher population doublings, multilineage differentiation capacity, no risk for developing immune reactions or rejection following transplantation exist, and no immunosuppressive therapy is needed.

Apparently, SHED represents a population of multipotent stem cells that perhaps more immature than previously examined postnatal stromal stem cell populations. SHED can form sphere-like cell cluster and obtained naturally or non-invasively from almost every human being resulting in minimal or no pain or discomfort. During long-term cultivation, it does not show any signs of degeneration or spontaneous differentiation. ${ }^{25,26,27}$

Several studies with flow cytometry analysis which used a panel of cell surface markers revealed expression pattern for a variety of markers for SHED. A study showed 
that ex vivo-expanded SHED was found to express the cell surface molecules STRO-1 and CD146. ${ }^{25}$ Others studies showed that SHED was also expressed positivity for CD90, CD73, CD105, CD44, CD13, Nestin, DCX, BIII-tubulin, NeuN, GFAP, S-100, A2B5, CNPase Nanog, Oct3/4 and SSEAs (-3, -4). However, other studies described that SHED is negative for CD14, CD45 and CD34 while other studies showed that SHED is negative for CD11b, CD19 and CD43. ${ }^{18,25,28,29}$

Several studies described that SHED could differentiate in vitro and in vivo into adipocytes which can be used to treat many spine and orthopedic conditions, Crohn's disease and cardiovascular diseases. It may also be useful in plastic surgery. Besides that, SHED can differentiate into osteoblasts, hepatocytes, neural cells, chondrocytes, myocytes, skin cells, liver cells and odontoblasts. ${ }^{25,30,31}$

\section{PDLSC}

The periodontium is a soft connective tissue surrounding and supporting the tooth, including cementum, PDL and alveolar bone that function as an integrated unit. It is functionally important for tooth support. Another important role of the PDL is to regulate alveolar bone volume and to serve as a cell reservoir for tissue homeostasis, contributes to tooth nutrition and regeneration, and during mastication, PDL acts as a sensory organ for the proper positioning of the jaws. ${ }^{32,33}$

The presence of multipotent postnatal PDLSC was first described from normal impacted third molar collected from 16 individuals aged 19-29 years. PDL was gently separated from the surface of the root, processed into singlecell suspensions, and expanded in vitro, providing a unique reservoir of stem cells from an accessible tissue resource. Immunohistochemical staining, RT-PCR, northern and western blot analysis were used to identify putative stemcell markers. The human PDLSC can also be isolated from human periodontium using a minimally invasive periodontal access flap surgery in healthy donors. ${ }^{32,34}$

Flow cytometry revealed that the isolated cells were positive for STRO-1 and CD146, CD44, CD90, CD105, CD166, Oct-3/4, Sox2, nanog and nestin antibodies. However it lacks the expression of CD45, CD34 and CD14 or CD11b, CD79a, or CD19 and HLA class II. ${ }^{29,32,35}$

PDLSC has demonstrated the ability to differentiate into periodontal tissues such as the cementoblast-like cell, PDL tissue repair and alveolar bone in experimental animal models. It can also differentiate into osteogenic, adipogenic, chondrogenic and typical neuronal morphology comparable with previously characterized BMSC. Therefore, PDLSC can potentially be isolated and expanded in vitro as an excellent cellular source for PDL regenerative therapies, with minimal discomfort due to invasive procedures commonly performed. . $^{32,34,36,37}$

\section{DFSC}

The human dental follicle is a fibrous ectomesenchymal tissue sac and part of the tooth germ. It surrounds the whole enamel organ and limits the dental papilla at early stages of tooth development. The dental follicle regulates the osteoclastogenesis and osteogenesis needed for tooth eruption and tooth root development of the periodontium that consists of three different types of tissues: the alveolar bone, the PDL and cementum. ${ }^{38,39}$

Under specific culture conditions, DFSC can differentiate into multiple lineages cell types such as osteoblasts, cementoblasts, adipocytes and neuron-like cells. ${ }^{39}$ DFSC possesses strong osteogenic capability to differentiate toward the osteoblast lineage..$^{40}$

Precursor cells isolated from dental follicle expressed nestin, ${ }^{38}$ STRO-1, Oct3/4, Sox-2, Nanog and Notch, and are negative for markers of hematopoietic lineage CD34 and CD117, and positive for CD44, CD29, CD90, and CD105, indicating that those cells are mesenchymal cells. DFSC can adhere to plastic and form colonies. ${ }^{39}$

\section{MSCs in accordance to the International Society for Cellular Therapy (ISCT)}

Historically, MSCs were first isolated and expanded from marrow aspirates of the iliac crest. ${ }^{41}$ It has more recently been demonstrated that MSCs can be isolated from other tissues, including fat, extracted teeth, periosteum and alveolar bone. ${ }^{25,32,42-45}$ Other studies have demonstrated that osteogenic cells can be isolated from alveolar bone tissues by various methodologies. ${ }^{43,45-48}$ Yet, only one of these has defined the cell populations as MSCs, according to ISCT, and none has described a standardized, predictable methodology for tissue harvest with a large population of patients. ${ }^{49}$

DMSCs are nonhematopoietic stromal cells that have important characteristic, in which they are capable of differentiating, proliferating and regenerating mesenchymal tissues such as bone, cartilage, marrow stroma, connective tissue, muscle, tendon, adipose and ligament. ${ }^{19,20}$. MSCs have 
the potential to differentiate into many different specialized cells in the body and serve to repair or regenerate the tissues depending on culture conditions and non-mesoderm-type cells. In addition, MSCs are also hypoimmunogenic and evade allorejection. MSCs express telomerase and can maintain it longer than other somatic cells. Not only that, they have enormous proliferative capacities and as the result MSCs are able to extend more than 10 passages in vitro without losing their original characteristics. ${ }^{50-52}$ Previous studies show that the proliferation and differentiation of stem cells are due to the influence of free radicals. Another study show that antioxidants obtained from herbal extracts also play role in differentiation and proliferation of MSCs. ${ }^{53}$

MSCs population could be found in every organ and tissue in the body such as umbilical cord, umbilical cord blood, peripheral blood, adult connective tissue, placenta, amniotic membrane, dental tissue and bone marrow. ${ }^{11}$ Recently, the use of human ASCs from bone marrow was widely explored for cell and gene therapy purposes. In specific culture condition, BM-MSCs have the ability to differentiate into several cell lineages including osteoblasts, adipocytes, chondrocytes, myoblasts and early progenitors of neural cells, comparable to PDLSC. ${ }^{54}$ Another example is MSCs found from lipoaspirate, a waste product from liposuction procedure. The MSCs from lipoaspirate is often called adipose-derived stem cells. ${ }^{55}$

In order to ensure the future use of MSCs, MSCs derived from tissues need to be preserved. Cyropreservation is one of the most important steps to ensure the future use of stem cells. Slow-cooling method of cryopreservation is the most frequently used to preserve various cells, tissues and organs. In addition to slow-cooling method, the previous research has shown that rapid-cooling method is a potential cryopreservation method. ${ }^{56}$

\section{Identification of MSCs}

Interest and research about MSCs have risen over the last two decades. A lot of investigation have been conducted and many laboratories develop methods to isolate and expand MSCs. However, the defining characteristics of MSCs are still inconsistent which lead to an inability of comparing and contrasting studies. Thus, the ISCT proposed three criteria in defining MSCs which are adherence to plastic, specific surface antigen $(\mathrm{Ag})$ expression and multipotent differentiation potential. ${ }^{49}$

\section{Plastic adherence}

Plastic adherence is a well-described property of MSC and unique subsets of MSCs. ${ }^{49}$ MSCs are often isolated by adherence selection in which the MSCs are placed in plastic tissue culture vessels and maintained under standard conditions. The nonadherent cells, such as hematopoietic cells, are removed while the remaining adherent cells are MSCs. $^{57}$

\section{Specific surface antigen (Ag) expression}

Surface antigen has been used for identification of a cell population. It has been shown that more than $95 \%$ of MSCs expressed CD105, CD73 and CD90, while less than 2\% of MSCs expressed hematopoietic Ag. Thus, ISCT proposed that MSCs must express CD105, CD73 and CD90, and lack in expressing the hematopoietic Ag. Some of the examples of hematopoietic Ag are CD45, CD34, CD14 or CD11b, CD79 or CD19 and HLA-DR.

CD105 is originally recognized by the Mab SH2 and known as endoglin. ${ }^{49} \mathrm{CD} 105$ is a membrane glycoprotein and plays an important role in angiogenesis. ${ }^{58} \mathrm{CD} 105$ is also a component of the receptor complex of transforming growth factor- beta (TGF- $\beta$ ) involved in cell proliferation, differentiation, migration and interactions between MSCs and hematopoietic cells. ${ }^{59,60}$ Studies also found that $\mathrm{CD} 105^{+}$ MSCs are capable of differentiating into adipogenic, osteogenic and chondrogenic lineages..$^{59,61}$ Besides CD105, MSCs should also express CD73, known as ecto 5 'nucleotidase (originally recognized by the Mab SH3 and SH4) and CD90, known as Thy- $1 .{ }^{49}$ CD90 is a cell surface anchored glycoprotein that is expressed on MSCs and have a role in cell motility as well in cell-cell and cell-matrix interactions. ${ }^{50,62}$

Several studies have shown that dental MSCs showed other cell surface antigen than CD105, CD73 and CD190 (Table 1). For instance, DPSC showed positive markers of CD146, STRO-1, CD106, CD29, CD51, CD61, CD166, ALDH1, 3G5, CD44, CD9, CD10, CD13, CD59, MSCA1, CD81, CD24 and several others. ${ }^{29,32,35}$ A possible reason for differential expression of antigens of DPSC may be the presence of different subpopulations of MSCs in dental pulp which has different biological activities. For example, a high proliferative DPSC showed the positive marker of CD44, CD90 and CD166, while DPSC with odonto-osteogenic properties expressed STRO-1. Another example is DPSC that has higher capacity of self-renewal and osteogenic differentiation, express CD34 and CD117.,23 
Table 1. Surface Antigen (Ag) expression of MSCs

\begin{tabular}{|c|c|c|c|}
\hline \multirow{2}{*}{$\begin{array}{l}\text { Type of } \\
\text { MSCs }\end{array}$} & \multirow{2}{*}{ References } & \multicolumn{2}{|l|}{ Antigen (Ag) expression marker } \\
\hline & & Positive & Negative \\
\hline DPSC & {$[13,16,17]$} & $\begin{array}{l}\text { CD73, C90, CD105, CD146, STRO-1, CD106, CD29, CD49, CD51, CD61, CD166, } \\
\text { CD117, ALDH1, 3G5, CD44, CD9, CD10 CD13, CD59, MSCA-1, CD81, CD24, } \\
\text { CD271, Nestin, DCX, BIII-tubulin, NeuN, GFAP, S-100, A2B5, CNPase, musashi-1, } \\
\text { p75, snail (-1, -2), slug, Sox-9 Nanog, Oct3/4, SSEA }(-1,-3,-4,-5) \text {, Notch }(-1,-2,-3)\end{array}$ & $\begin{array}{l}\text { CD14, CD19, CD34, CD } 45, \text { CD133, } \\
\text { HLA-DR }\end{array}$ \\
\hline SHED & {$[17,24,27,28]$} & $\begin{array}{l}\text { CD90, CD73, CD105, CD44, CD13, Nestin, DCX, BIII-tubulin, NeuN, GFAP, S-100, } \\
\text { A2B5, CNPase Nanog, Oct3/4, SSEA }(-3,-4)\end{array}$ & CD14, CD45, CD34, CD19, CD43 \\
\hline PDLSC & {$[28,31,34]$} & CD105, CD90, CD73, STRO-1, CD146, CD117 & CD45, CD34, CD14, CD19, HLA class II \\
\hline SCAP & {$[20,21,22,23]$} & CD146, CD44, CD73, CD90, CD105, CD106, STRO-1, CD24 & CD18, CD34, CD45, HLA-DR \\
\hline DFSC & {$[12,37,38]$} & Nestin, STRO-1, Oct3/4, Sox-2, Nanog, and Notch, CD44, CD29, CD90, CD105 & CD14, CD31, CD34, CD35, CD117 \\
\hline
\end{tabular}

\section{Multipotent differentiation potential}

Stem cells are categorized by their potential to differentiate into other types of cells which are totipotent, pluripotent, multipotent and unipotent. Multipotent stem cells have the ability differentiate into all cell types within one particular lineage and self-renewing. ${ }^{63}$ Although multipotent stem cells can produce other lines of cells, it is limited in its capacity of differentiation. Various research has established that this specific stem cell can differentiate into different tissue such as bone, muscle, cartilage, fat and other related tissues. ${ }^{64}$

MSCs seem to have the potency which surpassed the formerly supposed restrictions for generating different cell types. This potential result of plasticity can be applied in stem cell therapy. It means that if researchers can arrange this differentiation, for example, a blood stem cell could be applied as a substitute for other tissues. Multipotent Stem cells have been applied in treatment of different disorders such as spinal cord injury, bone fracture, autoimmune diseases, rheumatoid arthritis, hematopoietic defects and fertility preservation. ${ }^{65}$

Multipotent MSCs has the capability of self-renewing and differentiating into various cell lineages. ${ }^{66}$ Therefore, MSCs are promising cells for tissue engineering. MSCs are key to regenerative wound healing. MSCs orchestrate wound repair by structural repair via cellular differentiation, immune-modulation, secretion of growth factors that drive neovascularization, re-epithelialization and mobilization of resident stem cells. ${ }^{67}$ Not only that, MSCs have significant clinical implications in immunosuppressive and antiinflammatory effects through the interactions between the lymphocytes associated with both the innate and adaptive immune systems. MSCs suppress T cell proliferation, B cell functions, natural killer cell proliferation and cytokine production. It also prevent the differentiation, maturation, and activation of dendritic cell.

\section{Conclusion}

MSCs are ASCs that could be found in our body tissues such as dental tissues. Dental MSCs are described as non-hematopoietic stromal cells with the capability to differentiate into many different cells in the body and serve to develop, repair and regenerate the mesenchymal tissues. There are several types of dental MSCs depending on the tissue origin, such as DPSC, SCAP, SHED, which have difference in membrane biomarkers and the ability to differentiate, repair and regenerate.

\section{References}

1. Volponi AA, Pang Y, Sharpe PT. Stem cell-based biological tooth repair and regeneration. Trends Cell Biol. 2010; 20(12): 715-22.

2. Sandra F, Sudiono S, Binartha CTO, Chouw A, Djamil MS. Growth and Osteogenic Differentiation of CD117+ Dental Pulp and Periodontal Ligament Cells. Indones Biomed J. 2017; in press.

3. Ledesma-Martínez E, Mendoza-Núñez V, Santiago-Osorio E. Mesenchymal Stem Cells Derived from Dental Pulp: A Review. Stem Cells Int. 2016; 2016: 4709572. doi: 10.1155/2016/4709572.

4. Yu T, Volponi AA, Babb R, An Z, Sharpe PT. Stem Cells in Tooth Development, Growth, Repair, and Regeneration. Curr Top Dev Biol. 2015; 115: 187-212.

5. Arthur A, Shi S, Gronthos S. Dental Pulp Stem Cells. In: Vishwakarma A, Sharpe P, Shi Songtau, Ramalingam M, editors. Stem Cell Biology and Tissue Engineering in Dental Sciences. Oxford: Elsevier Inc; 2015. p. 279-89.

6. Sharpe PT. Dental msenchymal stem cells. Development. 2016; 143: 2273-80.

7. Cho SW, Hwang HJ, Kim JY, Song WC, Song SJ, Yamamoto H, et al. Lineage of non-cranial neural crest cell in the dental mesenchyme: using a lacZ reporter gene during early tooth development. J Electron Microsc (Tokyo). 2003; 52(6): 567-71.

8. Zhang Y, Wang S, Song Y, Han J, Chai Y, Chen Y. Timing of odontogenic neural crest cell migration and tooth-forming capability in mice. Dev Dyn. 2003; 226(4): 713-8.

9. Li J, Huang X, Xu X, Mayo J, Bringas P, Jiang R et al. SMAD4mediated WNT signaling controls the fate of cranial neural crest cells during tooth morphogenesis. Development. 2011; 138(10): 1977-89. 
10. Chai Y, Jiang X, Ito Y, Bringas PJr, Han J, Rowitch DH, et al. Fate of the mammalian cranial neural crest during tooth and mandibular morphogenesis. Development. 2000; 127(8): 1671-9.

11. Rodríguez-Lozano FJ, Insausti CL, Iniesta F, Blanquer M, Ramírez MD, Meseguer L, et al. Mesenchymal dental stem cells in regenerative dentistry. Med Oral Patol Oral Cir Bucal. 2012; 17(6): e1062-7.

12. Huang GT, Gronthos S, Shi S. Mesenchymal Stem Cells Derived from Dental Tissues vs. Those from Other Sources: Their Biology and Role in Regenerative Medicine. J Dent Res. 2009; 88(9): 792806.

13. Shilpa PS, Kaul R, Sultana N, Bhat S. Stem cells: Boon to dentistry and medicine. Dent Res J (Isfahan). 2013; 10(2): 149-54.

14. Gronthos S, Mankani M, Brahim J, Robey PG, Shi S. Postnatal human dental pulp stem cells (DPSCs) in vitro and in vivo. Proc Natl Acad Sci USA. 2000; 97(25): 13625-30.

15. Alge DL, Zhou D, Adams LL, Wyss BK, Shadday MD, Woods EJ, et al. Donor-matched comparison of dental pulp stem cells and bone marrow-derived mesenchymal stem cells in a rat model. J Tissue Eng Regen Med. 2010; 4(1): 73-81.

16. Murray PE, Garcia-Godoy F, Hargreaves KM. Regenerative endodontics: A review of current status and a call for action. J Endod. 2007; 33(4): 377-90.

17. Kerkis I, Kerkis A, Dozortsev D, Stukart-Parsons GC, Gomes Massironi SM, Pereira LV, et al. Isolation and characterization of a population of immature dental pulp stem cells expressing OCT-4 and other embryonic stem cell markers. Cells Tissues Organs. 2006; 184(3-4): 105-16.

18. Bakopoulou A, About I. Stem Cells of Dental Origin : Current Research Trends and Key Milestones towards Clinical Application. Stem Cell Int. 2016; 2016: 4209891. doi: 10.1155/2016/4209891.

19. Potdar PD, Jethmalani YD. Human dental pulp stem cells: Applications in future regenerative medicine. World J Stem Cells. 2015; 7(5): 839-51.

20. Gomes JA, Geraldes Monterio B, Melo GB, Smith RL, Cavenaghi Pereira da Silva M, Lizier NF, et al. Corneal reconstruction with tissue-engineered cell sheets composed of human immature dental pulp stem cells. Invest Ophthalmol Vis Sci. 2010; 51(3): 1408-14.

21. Tran HLB, Dinh TTH, Nguyen HTT. Stem cells from apical papilla and their properties in two primary culture methods. International Journal of Biomedical Research. 2014; 5(8): 516-21.

22. Ruparel NB, de Almeida JF, Henry MA, Diogenes A. Characterization of a stem cell of apical papilla cell line: effect of passage on cellular phenotype. J Endod. 2013; 39(3): 357-63

23. Sonoyama W, Liu Y, Yamaza T, Tuan RS, Wang S, Shi S, et al. Characterization of the apical papilla and its residing stem cells from human immature permanent teeth: a pilot study. J Endod. 2008; 34(2): 166-71.

24. Morsczeck C. Dental Follicle Stem Cells. In: Vishwakarma A, Sharpe P, Shi Songtau, Ramalingam M, editors. Stem Cell Biology and Tissue Engineering in Dental Sciences. Oxford: Elsevier Inc; 2015. p.271-77.

25. Miura M, Gronthos S, Zhao M, Lu B, Fisher LW, Robey PG, et al. SHED: Stem cells from human exfoliated deciduous teeth. Proc Natl Acad Sci U S A. 2003; 100(10): 5807-12.

26. Suchánek J, Visek B, Soukup T, El-Din Mohamed SK, Ivančaková R, Mokrý J et al. Stem cells from human exfoliated deciduous teeth-isolation, long term cultivation and phenotypical analysis. Acta Medica (Hradec Kralove). 2010; 53(2): 93-9.

27. Martinez Saez D, Sasaki RT, Neves AD, da Silva MC. Stem Cells from Human Exfoliated Deciduous Teeth: A Growing Literature. Cells Tissues Organs. 2016; 202(5-6): 269-80.

28. Wang X, Sha XJ, Li GH, Yang FS, Ji K, Wen LY, et al. Comparative characterization of stem cells from human exfoliated deciduous teeth and dental pulp stem cells. Arch Oral Biol. 2012; 57(9): 123140.

29. Saito MT, Silvério KG, Casati MZ, Sallum EA, Nociti FH Jr. Toothderived stem cells: Update and perspectives. World J of Stem Cells. 2015; 7(2): 399-407.

30. Nourbakhsh N, Soleimani M, Taghipour Z, Karbalaie K, Mousavi $\mathrm{SB}$, Talebi A, et al. Induced in vitro differentiation of neural-like cells from human exfoliated deciduous teeth-derived stem cells. Int J Dev Biol. 2011; 55(2): 189-95.

31. Bansal R, Jain A. Current overview on dental stem cells applications in regenerative dentistry. J Nat Sci Biol Med. 2015; 6(1): 29-34.

32. Seo BM, Miura M, Gronthos S, Bartold PM, Batouli S, Brahim J, et al. Investigation of multipotent postnatal stem cells from human periodontal ligament. Lancet. 2004; 364(9429): 149-55.

33. Barczyk M, Bolstad AI, Gullberg D. Role of integrins in the periodontal ligament: organizers and facilitators. Periodontol 2000. 2013; 63(1): 29-47.

34. Diomede F, Zini N, Gatta V, Fulle S, Merciaro I, D’Aurora M, et al. Human periodontal ligament stem cells cultured onto corticocancellous scaffold drive bone regenerative process. Eur Cell Mater. 2016; 32: 181-201.

35. Seo BM, Miura M, Sonoyama W, Coppe C, Staynon R, Shi S. Recovery of stem cells from cryopreserved periodontal ligament. J Dent Res. 2005; 84(10): 907-12.

36. Gay IC, Chen S, MacDougall M. Isolation and characterization of multipotent human periodontal ligament stem cells. Orthod Craniofac Res. 2007; 10(3): 149-60.

37. Zhu W, Liang M. Periodontal ligament stem cells: current status, concerns, and future prospects. Stem Cells Int. 2015; 2015: 972313. doi: $10.1155 / 2015 / 972313$.

38. Lucaciu O, Sorițău O, Gheban D, Ciuca DR, Virtic O, Vulpoi A, et al. Dental follicle stem cells in bone regeneration on titanium implants. BMC Biotechnol. 2015; 15: 114. doi: 10.1186/s12896-015-0229-6.

39. Rezai-Rad M, Bova JF, Orooji M, Pepping J, Qureshi A, Del Piero $\mathrm{F}$, et al. Evaluation of bone regeneration potential of dental follicle stem cells for treatment of craniofacial defects. Cytotherapy. 2015; 17(11): 1572-81.

40. Priya SP, Higuchi A, Fanas SA, Ling MP, Neela VK, Sunil PM, et al. Odontogenic epithelial stem cells: hidden sources. Lab Invest. 2015; 95(12): 1344-52.

41. Zuk PA, Zhu M, Mizuno H, Huang J, Futrell JW, Katz AJ, et al. Multilineage cells from human adipose tissue: implications for cellbased therapies. Tissue Eng. 2001; 7(2): 211-28.

42. Matsubara T, Suardita K, Ishii M, Sugiyama M, Igarashi A, Oda R, et al. Alveolar bone marrow as a cell source for regenerative medicine: differences between alveolar and iliac bone marrow stromal cells. J Bone Miner Res. 2005; 20(3): 399-409.

43. Akintoye SO, Lam T, Shi S, Brahim J, Collins MT, Robey PG. Skeletal site-specific characterization of orofacial and iliac crest human bone marrow stromal cells in same individuals. Bone. 2006; 38(6): 758-68.

44. Crisan M, Yap S, Casteilla L, Chen CW, Corselli M, Park TS, et al. A perivascular origin for mesenchymal stem cells in multiple human organs. Cell Stem Cell. 2008; 3(3): 301-13.

45. Mailhot JM, Borke JL. An Isolation and In Vitro Culturing Method for Human Intraoral Bone Cells Derived from Dental Implant 
Preparation Sites. Clin Oral Implants Res. 1998; 9(1): 43-50.

46. Cicconetti A, Sacchetti B, Bartoli A, Michienzi S, Corsi A, Funari A, et al. Human Maxillary Tuberosity and Jaw Periosteum as Sources of Osteoprogenitor Cells for Tissue Engineering. Oral Surg Oral Med Oral Pathol Oral Radiol Endod. 2007; 104(5): 618.e1-12.

47. Jo YY, Lee HJ, Kook SY, Choung HW, Park JY, Chung JH, et al. Isolation and Characterization of Postnatal Stem Cells from Human Dental Tissues. Tissue Eng. 2007; 13(4): 767-73.

48. Dominici M, Le Blanc K, Mueller I, Slaper-Cortenbach I, Marini F, Krause D, et al. Minimal Criteria for Defining Multipotent Mesenchymal Stromal Cells. The International Society for Cellular Therapy Position Statement. Cytotherapy. 2006; 8(4): 315-7.

49. Lubis AM, Sandhow L, Lubis VK, Noor A, Gumay F, Merlina M, et al. Isolation and Cultivation of Mesenchymal Stem Cells from Iliac Crest Bone Marrow for Further Cartilage Defect Management. Acta Med Indones. 2011; 43(3): 178-84.

50. Mao X, Liu Y, Chen C, Shi S. Mesenchymal Stem Cells And Their Role In Dental Medicine. Dent Clin North Am. 2017; 61(1): 161-72

51. Ryan JM, Barry FP, Murphy JM, Mahon BP. Mesenchymal Stem Cells Avoid Allogeneic Rejection. J Inflamm (Lond). 2005; 2: 8. doi: 10.1186/1476-9255-2-8.

52. Widowati W, Sardjono CT, Wijaya L, Laksmitawati DR, Sandra F. Extract of Curcuma longa L. and (-)-Epigallocatechin-3-Gallate Enhanced Proliferation of Adipose Tissue-derived Mesenchymal Stem Cells (AD-MSCs) and Differentiation of AD-MSCs into Endothelial Progenitor Cells. Journal of US-China Med Sci. 2012; 9(1): 22-9.

53. Sardjono CT, Setiawan M, Frisca, Saputra V, Aniko G, Sandra F. Application of a modified method for stem cell isolation from lipoaspirates in a basic lab. Med J Indones. 2009; 18(2): 91-6.

54. Bara J, Richards R, Alini M, Stoddart M. Concise review: Bone marrow-Derived Mesenchymal Stem Cells Change Phenotype Following In Vitro Culture: Implications for Basic Research and The Clinic. Stem Cells. 2014; 32(7): 1713-23.

55. Djuwantono T, Wirakusumah FF, Achmad TH, Sandra F, Halim D, Faried A. A comparison of cryopreservation methods: Slowcooling vs. rapid-cooling based on cell viability, oxidative stress, apoptosis, and CD34+ enumeration of human umbilical cord blood mononucleated cells. BMC Res Notes. 2011; 4: 371. doi: 10.1186/1756-0500-4-371.
56. Wijaya L, Agustina D, Lizandi AO, Kartawinata MM, Sandra F. Reversing Breast Cancer Stem Cell into Breast Somatic Stem Cell. Curr Pharm Biotechnol. 2011; 12(2): 189-95.

57. Mark P, Kleinsorge M, Gaebel R, Lux CA, Toelk A, Pittermann E, et al. Human Mesenchymal Stem Cells Display Reduced Expression of CD105 after Culture in Serum-Free Medium. Stem Cells Int 2013; 2013: 698076. doi: 10.1155/2013/698076.

58. Maleki M, Ghanbarvand F, Behvarz MR, Ejtemaei M, Ghadirkhomi E. Comparison of Mesenchymal Stem Cell Markers in Multiple Human Adult Stem Cells. Int J Stem Cells. 2014; 7(2): 118-26.

59. Barry FP, Boynton RE, Haynesworth S, Murphy JM, Zaia J. The monoclonal antibody SH-2, raised against human mesenchymal stem cells, recognizes an epitope on endoglin (CD105). Biochem Biophys Res Commun. 1999; 265(1): 134-9.

60. Roura S, Farré J, Soler-Botija C, Llach A, Hove-Madsen L, Cairó $\mathrm{JJ}$, et al. Effect of aging on the pluripotential capacity of human CD105+ mesenchymal stem cells. Eur J Heart Fail. 2006; 8(6): 55563.

61. Rege TA, Hagood JS. Thy-1 as a regulator of cell-cell and cell-matrix interactions in axon regeneration, apoptosis, adhesion, migration, cancer, and fibrosis. FASEB J. 2006; 20(8): 1045-54.

62. Ledda M, Fosca M, Bonis AD, Curcio M, Teghil R, Lolli MG, et al. Placenta Derived Mesenchymal Stem Cells Hosted on RKKP GlassCeramic: A Tissue Engineering Strategy for Bone Regenerative Medicine Applications. Biomed Res Int. 2016; 2016: 3657906. doi: 10.1155/2016/3657906.

63. Sobhani A, Khanlarkhand N, Baazm M, Mohammadzadeh F, Najafi A, Mehdinejadiani S, et al. Multipotent Stem Cell and Current Application. Acta Med Iran. 2017; 55(1): 6-23.

64. Halim D, Murti H, Sandra F, Boediono A, Djuwantono T, Setiawan B. Stem Cell: Dasar Teori \& Aplikasi Klinis. Jakarta: Erlangga; 2010.

65. Ren H, Sang Y, Zhang F, Liu Z, Qi N, Chen Y. Comparative Analysis of Human Mesenchymal Stem Cells from Umbilical Cord, Dental Pulp, and Menstrual Blood as Sources for Cell Therapy. Stem Cells Int. 2016; 2016: 3516574. doi: 10.1155/2016/3516574.

66. Balaji S, Keswani SG, Crombleholme TM. The Role of Mesenchymal Stem Cells in The Regenerative Wound Healing Phenotype. Adv Wound Care (New Rochelle). 2012; 1(4): 159-65.

67. Kim N, Cho SG. Clinical Applications of Mesenchymal Stem Cells Korean J Intern Med. 2013; 28(4): 387-402. 